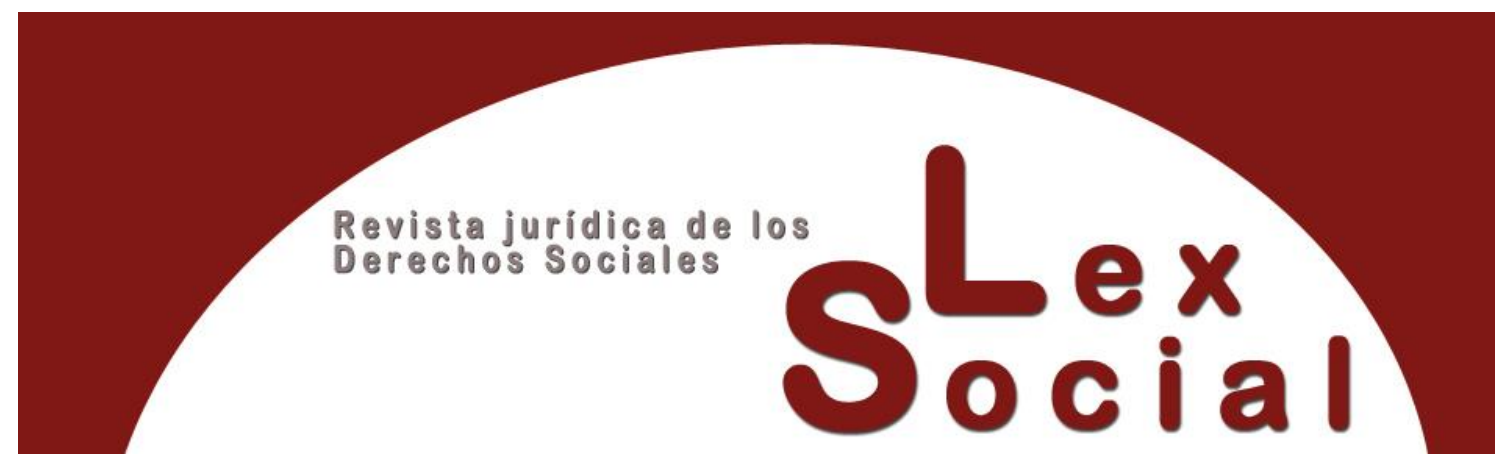

\title{
ESPAÑA Y LA OIT (1975-2000): UNA RELACIÓN MUTUAMENTE ENRIQUECEDORA
}

\section{SPAIN AND THE ILO (1975-2000): A MUTUALLY ENRICHING RELATIONSHIP}

JEAN-MICHEL SERVAIS

Profesor invitado, Universidad de Gerona, Presidente de honor de la Sociedad Internacional de Derecho del Trabajo y de la seguridad Social. Ex-director de la OIT. https://orcid.org/0000-0001-6665-8268

Cómo citar este trabajo: Servais, J-M. (2022). España y la OIT (1975-2000): una relación mutuamente enriquecedora Lex Social, Revista De Derechos Sociales, 12 (1), pp. 122-142. https://doi.org/10.46661/lexsocial.6422

\section{RESUMEN}

Esta contribución examina, en primer lugar, la situación laboral y sindical española en los últimos años del régimen franquista a la luz de la OIT. En este sentido, contiene un breve recordatorio de las estructuras sociales y sindicales presentes en España entre 1936 y 1975. En esta parte, no se trata tanto de rememorar las críticas a la situación existente durante la Dictadura como de subrayar los antecedentes de la dinámica iniciada, con la colaboración de la Organización de Ginebra, en el sistema de relaciones laborales a partir de 1975, así como la rápida creación de un sistema social democrático.

A continuación, se analizan las reformas de mayor calado instituidas tras el cambio de régimen. Para ello, se describen los logros ejemplares del país en los años inmediatamente siguientes. Se concluye extrayendo algunas lecciones de una transición particularmente corta y exitosa que pueden resultar útiles para otros países que se encuentren en el paso de un régimen totalitario a uno democrático, a partir de la reflexión del papel de las instituciones nacionales en la interpretación e implementación de los convenios internacionales sobre los derechos fundamentales

\section{$(c))$ EY-NC-SA}


Palabras Clave: OIT, sindicalismo español, derechos sociales, libertades públicas, franquismo.

\begin{abstract}
The contribution first examines the social and trade union situation in Spain in the last years of the Franco regime from the point of view of the ILO. It contains a brief reminder of the social and trade union structures from 1936 to 1975. The intention in this part is less to recall the criticisms than to underline the background of the dynamic set in motion by the country, with the collaboration of the Geneva Organization, since 1975 , and the rapid creation of a democratic social system.

It deals then with the major reforms intervened after the regime change. It describes the exemplary achievements of the country in the years immediately following. The conclusions draw some lessons from a particularly short and successful transition from a totalitarian to a democratic regime, reflecting on the role of national institutions in the interpretation and implementation of international conventions on fundamental rights.
\end{abstract}

KeYwORDS: ILO, Spanish trade-unionism, social rights, civil liberties, Franco regime.

SUMARIO

\title{
I. Introducción
}

II La situación laboral y sindical en España antes de 1975.

1. Las relaciones individuales de trabajo.

2. Las relaciones colectivas de trabajo.

III. La situación laboral y sindical en España entre los años 1975 y 2000.

1. La misión de la OIT en 1983.

2. Puntos principales.

2.1. La devolución del patrimonio de la antigua organización corporativa.

2.2. Pactos sociales.

2.3. La ausencia de procedimientos eficaces de conciliación, mediación y arbitraje voluntario.

2.4. Las relaciones laborales en la Administración Pública.

3. Años posteriores.

IV. Algunas reflexiones finales sobre una transición particularmente corta y exitosa 
1. Los métodos de interpretación y de aplicación de los instrumentos jurídicos sobre las libertades civiles y sociales.

2. El papel de las instituciones nacionales.

Bibliografía

Anexo

\section{Introducción}

Entre los años 70 y 80, tuve la suerte de participar directamente en un momento crucial en la historia de las relaciones de España con la Organización internacional del Trabajo. En particular me instalé en el país desde finales del mes de noviembre de 1983 hasta mediados de diciembre del mismo año para analizar de una manera crítica la situación sindical y las relaciones laborales en la etapa final del período franquista. La misión que tenía encargada respondía a resoluciones adoptadas por las Conferencias regionales europeas de la OIT durante el decenio de 1980, periodo histórico para nuestro Continente en el cual se realizaron también otras investigaciones de este tipo en Hungría, Yugoslavia, Austria y Noruega.

La misión y el informe resultante ${ }^{1}$ fueron recibidos positivamente, provocando reformas en la legislación y en la práctica de las relaciones laborales del país. Esta contribución constituye un testimonio de mi experiencia.

Se ha señalado, no sin razón, que España ha sabido conducir la transición de un régimen totalitario a la democracia de una manera sorprendentemente pacífica y ordenada. No se produjeron las turbulencias esperadas, a diferencia de lo que ocurrió en otros países con experiencias equivalentes. Se evitaron los escollos políticos en un clima de libertades públicas y ello a pesar de una seria crisis económica, de las tensiones relacionadas con reivindicaciones autonomistas así como de la preocupación generada por grupos terroristas en el País Vasco ${ }^{2}$.

En la primera parte de mi contribución examino desde el punto de vista internacional de la OIT, la situación laboral y sindical en España en los últimos años del franquismo. Empieza con un breve recordatorio de las estructuras sociales y sindicales existentes entre 1936 y 1975. La intención en esta parte no consiste tanto en rememorar las críticas a la situación existente durante la Dictadura sino en subrayar los antecedentes de la dinámica impresionante puesta en movimiento por el país, con la colaboración de la Organización de Ginebra, a partir de 1975 con el fin de establecer una estructura social democrática. Es más, una breve revisión de este periodo puede aclarar algunos aspectos de la situación presente.

\footnotetext{
${ }^{1}$ OIT, Situación sindical y relaciones laborales en España, Ginebra, OIT, 1985.

${ }^{2}$ De la Villa Gil, Luis Enrique, Panorama de las relaciones laborales en España, Madrid, Editorial Tecnos, 1983, pág.8.
} 
En la segunda parte se analizan las reformas más relevantes introducidas después del cambio de régimen. Se describen los logros ejemplares del país en los años inmediatamente siguientes. No obstante, no me extenderé en el detalle de los últimos años, especialmente en la manera en la que España ha afrontado la crisis de 2008, período al que ya he dedicado otro estudio ${ }^{3}$. En las conclusiones, pretendo extraer algunas lecciones de una transición corta y exitosa desde una dictadura a una democracia, reflexionando sobre el papel de las instituciones nacionales en la interpretación y la implementación de los convenios internacionales sobre los derechos fundamentales.

\section{La situación laboral y sindical en España antes de 1975}

España dejó de ser Estado Miembro de la OIT desde 1941 hasta $1956^{4}$. A partir de 1957, el Comité de Libertad Sindical de la Organización (CLS) examinó varias quejas recibidas de organizaciones de trabajadores. Se referían a violaciones de la libertad sindical en el país. Cabe recordar que este procedimiento no requiere $-\mathrm{y}$ ahí reside su originalidad- la ratificación por parte del Estado afectado de ningún Convenio sobre libertad sindical.

En 1967, el Gobierno español buscó una salida a estos problemas y, después de contactos informales, sugirió que el Consejo de Administración de la OIT designase un grupo de estudio integrado por personas imparciales y objetivas con el objetivo de facilitar las informaciones que aclarasen la situación laboral y sindical en el país. Se entendió que este método, dirigido más a la recopilación y análisis de información que a la formulación de conclusiones y recomendaciones, era más viable debido a la situación política de la época. El procedimiento más formal del establecimiento de una Comisión de investigación y conciliación habría requerido el consentimiento hipotético del Estado para examinar la aplicación de instrumentos internacionales que no había ratificado.

Este gesto, por tímido que fuera, correspondía a una voluntad más genérica de apertura al exterior por parte del Gobierno patente a partir de 1959 que iba acompañada de la implementación de una nueva política económica. El Grupo de Estudio no tenía asignado el encargo de una investigación. Por el contrario, su mandato consistía en la presentación de un informe al Consejo de Administración de la OIT a la luz de los principios de la Organización. Su miembros se habían comprometido en desempeñar su tarea "con honor y fidelidad, completa imparcialidad y con toda conciencia"5.

Los miembros de la misión visitaron España del 7 al 30 de marzo de 1969 encabezados por Wilfred Jenks, alto funcionario y futuro Director General de la OIT, quien dirigía su secretaria. Como principal resultado, elaboraron un informe, titulado La situación laboral

\footnotetext{
${ }^{3}$ Servais, Jean-Michel, "España y las normas de la OIT o cómo renovar una bella historia" en Gil y Gil, Jose Luis (coord.), España y la OIT. 100 años de diálogo en un mundo cambiante, Madrid, Ediciones Cinca, 2018, págs. 27-57.

${ }^{4}$ OIT, La situación laboral y sindical en España que fue publicado, Ginebra, 1969, § 341 .

${ }^{5}$ OIT, op.cit. $\S 1137$.
} 
y sindical en España, que fue publicado en el año $1969^{6}$. En él, se describe con gran precisión el panorama social del país poco antes del cambio de régimen, partiendo en su análisis de la distinción entre relaciones individuales y colectivas de trabajo.

\section{Las relaciones individuales de trabajo}

La legislación laboral, que se inicia verdaderamente a principios del siglo pasado, había alcanzado una amplia extensión en el año 1936 y buena parte de estas normas permanecieron vigentes durante la Dictadura. El Gobierno franquista continuó desarrollando la red normativa en materia social principalmente a través del sistema de reglamentaciones. La seguridad social creció con mayor intensidad después de la Guerra Civil hasta llegar a cubrir todas las contingencias que se protegen normalmente en los sistemas de previsión social, amparando a la gran mayoría de los asalariados y, en algunas ramas, a sectores de autónomos ${ }^{7}$.

España había ratificado un número importante de convenios de la OIT (en concreto, 55) entre 1923 y 1969, incluso algunos que se refieren a derechos fundamentales en el trabajo: por ejemplo, los Convenios núms. 29 y 105 sobre la abolición del trabajo forzoso, (1930), núm. 111 relativo a la discriminación en el empleo y la profesión (1958) y núm. 100, sobre igualdad de remuneración $(1951)^{8}$.

Los órganos de control de la OIT no habían señalado discrepancias mayores entre la legislación de la época y los Convenios respectivos. Sin embargo, los salarios y las prestaciones otorgadas por la seguridad social, que se calculaban en base a ciertos elementos de la remuneración, continuaban de manera general siendo bajos ${ }^{9}$.

En pocas palabras, las condiciones individuales de trabajo y el régimen general de la seguridad social no fueron el objeto de críticas particulares aun cuando el desarrollo económico se encontraba a la zaga de los países de la Unión Europea.

\section{Las relaciones colectivas de trabajo}

En el campo de las grandes libertades sindicales, España solamente había ratificado en 1932- el Convenio núm. 11 sobre el derecho de asociación (agricultura), 1921, y no los instrumentos internacionales básicos en la materia, es decir los convenios núm. 87 sobre la libertad sindical y la protección del derecho de sindicación (1948) y núm. 98 sobre el derecho de sindicación y de negociación colectiva (1949).

El régimen franquista había instituido un sistema de sindicatos verticales por rama de actividad o servicio que debía integrar a todos los ciudadanos que participasen en el proceso de producción ya sea como trabajadores o como empleadores. Organismos unitarios agrupaban a empresarios y trabajadores, según un orden jerárquico, bajo la dirección del Estado; la afiliación y el pago de cotizaciones eran obligatorios. Crear

\footnotetext{
${ }^{6}$ OIT, op.cit., 1969.

${ }^{7}$ OIT, 1969, op.cit, $\$ 1161$ y 1165.

${ }^{8}$ OIT, op.cit, $\S 334,344$.

${ }^{9}$ OIT, op.cit, § 1168-1170.
} 
asociaciones al margen de estas corporaciones constituía un delito penal. Por eso, los órganos de control de la OIT subrayaron a menudo la contradicción fundamental existente entre la legislación entonces en vigor y los principios de la libertad sindical.

La intervención de la organización sindical oficial en la vida política provenía de su consideración primordial como instrumento del Estado y como representación pública. Durante la visita del Grupo de estudio, se señaló reiteradamente la gran importancia que había adquirido el patrimonio de la organización sindical oficial y las elevadas cifras que alcanzaba su presupuesto anual ${ }^{10}$.

A pesar de esta estructura de inspiración fascista, se observó que existían, principalmente en las regiones más industrializadas, otros dos tipos de asociaciones que los trabajadores habían creado ilegalmente. El primer tipo estaba constituido por las organizaciones de trabajadores disueltas y declaradas fuera de la ley que, reconstituidas por sus dirigentes en el extranjero, habían seguido participando en el movimiento sindical internacional y también, habían mantenido su presencia en España en condiciones difíciles y desarrollado ciertas actividades en la clandestinidad. Entre ellas figuraban la Unión General de Trabajadores (UGT), la Confederación Nacional del Trabajo (CNT) y la Solidaridad de Trabajadores Vascos (STV).

El otro tipo, considerado generalmente como espontaneo, surgió en torno a 1960, en núcleos de trabajadores que consideraban necesario contar con representantes que tuvieran toda su confianza para la discusión de convenios colectivos. Sería el germen de "Comisiones Obreras" que alrededor del año 1966 empezaron a disfrutar de una cierta tolerancia por parte del Régimen. Se consideraban un movimiento y no una organización, y sólo admitían la participación en su seno de trabajadores a título individual. Parecían dominadas por elementos políticos, comunistas en su mayoría, aunque también por sectores católicos. En todo caso sus líderes practicaron lo que se conoció como el "entrismo" para integrar de una manera u otra la organización sindical oficial y trabajar desde dentro ${ }^{11}$.

En esta época, los conflictos de trabajo debían resolverse, en último término, por las autoridades administrativas del trabajo o la magistratura laboral. Los órganos de control de la OIT también señalaron que las disposiciones sobre huelga podían interpretarse como una prohibición general de este medio de acción. Sin embargo, las estadísticas revelaban que las huelgas, a pesar de ser ilegales, constituían una marcada curva ascendente, hallándose motivadas principalmente por las reivindicaciones salariales. Además, en muchos casos las autoridades y los empleadores no tomaban medidas contra los huelguistas, frecuentemente para evitar que empeorase el clima laboral y resultara más difícil alcanzar una solución del conflicto. ${ }^{12}$

\footnotetext{
${ }^{10}$ OIT, op.cit, § 1223 y 1219.

${ }^{11}$ OIT, op.cit, §1232-1233; OIT, Situación sindical y relaciones laborales en España, Ginebra, OIT, 1985, págs 21-25.

12 OIT, 1969, op.cit, § 1181 y 1183.
} 
El Grupo de estudio subrayó la existencia de tres factores que tenían una importancia capital para las perspectivas de un dialogo fructífero sobre el desarrollo futuro de la situación sindical: el fin del estado de excepción, una investigación sobre los alegados malos tratos a sindicalistas y la amnistía o el indulto de sindicalistas encarcelados ${ }^{13}$.

La reglamentación de las relaciones colectivas de trabajo correspondía a la autoridad administrativa: el Ministerio de Trabajo promulgaba reglamentos por sector de actividad (o para una empresa que tuviera una importancia particular); en los que se fijaban las normas mínimas de trabajo. Desde 1958, con la promulgación de una ley de convenios colectivos sindicales, la negociación colectiva progresaba dentro del sistema sindical oficial. Ello había permitido ir complementando o sustituyendo el régimen anterior de regulación de las condiciones de trabajo en las distintas ramas de actividad, consistente en la adopción de reglamentaciones. ${ }^{14}$

En retrospectiva, llama la atención la analogía, desde el punto de vista de los derechos fundamentales en el ámbito laboral, de esta situación con la de los regímenes igualmente totalitarios, pero comunistas de la Europa del Este, lo cual no resulta extraño pues estos derechos se basan en la democracia. Analizo esta cuestión con más extensión en la segunda parte de la contribución.

\section{La situación laboral y sindical en España entre los años 1975 y 2000}

El sistema se liberaliza rápidamente después de la muerte del general Franco. Hubo una cierta indecisión sobre el modelo sindical a adoptar. Al principio, se observaron otras dificultades, incluso algunas violencias. Sin embargo, en el ámbito social, España es un valioso ejemplo de la utilización de los instrumentos de la OIT para democratizarse, como lo haría Polonia después en 1989. El 1 de abril de 1977 se adoptaba una ley que reconocía la libertad sindical; derecho que también se incluiría en la nueva Constitución de 27 diciembre de 1978. Además, ya se habían ratificado en 1977 los instrumentos internacionales básicos en la materia, es decir los convenios núm. 87 y núm. 98 de la OIT.

En este sentido, el Estado español aplicó cuidadosamente las normas de la OIT en materia de libertad sindical, de libre negociación colectiva y de igualdad de oportunidades y de tratamiento. De hecho, no solo se introdujeron en la legislación las disposiciones que corresponden al contenido de estos Convenios, sino que además se respetaron los principios formulados por los órganos de control de la Organización en la interpretación de estos instrumentos.

Reaparecieron los sindicatos libres, en particular CCOO y la UGT. Otras organizaciones de trabajadores se forjaron a partir de convicciones nacionalistas en las

\footnotetext{
${ }^{13}$ OIT, 1969, op.cit, $\$ 1142$.

${ }^{14}$ Sin embargo, se suspendió la negociación colectiva y se congelaron los salarios entre 1967 y 1969 (OIT, La situación laboral y sindical en España, Ginebra, OIT, 1969, § 860, 866, 871 y 1170).
} 
regiones catalana, gallega y vasca ${ }^{15}$. La Unión Sindical Obrera (USO) se inspiraba en los principios de la doctrina social cristiana y en un determinado momento llegó a adoptar posiciones de auto gestión. La tasa de sindicación se mantuvo baja e incluso descendió al $13.6 \%$ en el año 2018 (OECD, 2020). Paralelamente, los empresarios sintieron la necesidad de agruparse fuera de la organización corporativa, llamada a desaparecer. Surgieron así nuevas federaciones y confederaciones a partir, en muchos casos, de los antiguos "consejos de empresarios" que existían en la organización franquista. Este fenómeno explicaría, al menos en parte, el índice particularmente elevado de afiliación a la Confederación Española de Organizaciones Empresariales (CEOE) ${ }^{16}$.

\section{La misión de la OIT en 1983}

Los miembros de la misión, Efrén Córdoba, Arturo Bronstein, Jorge Castaño, además de yo mismo, todos funcionarios de la OIT, permanecimos en España desde el 27 de noviembre al 16 de diciembre de 1983. Fuimos recibidos por el Ministro del Trabajo y Seguridad Social y sus colaboradores y por los consejeros de trabajo de la Generalidad de Cataluña, del Gobierno Vasco y de Andalucía. Nos reunimos con numerosos altos funcionarios, entre ellos la Jefa de la Inspección Central de Trabajo y Seguridad Social, el Director General de Empleo, la Directora del Instituto Nacional de Emigración, así como los Directores Provinciales de Trabajo y Seguridad Social de Barcelona, Bilbao y Sevilla. También nos entrevistamos con el Director del Instituto de Mediación, Arbitraje y Conciliación, con el Presidente del Consejo de Relaciones Laborales de Andalucía, el profesor Miguel Rodríguez Piñero, y con el Secretario General del Consejo de Relaciones Laborales del País Vasco.

Además, visitamos la sede de la Confederación Española de Organizaciones Empresariales (CEOE), y de las Confederaciones de empleadores de Cataluña, País Vasco y Andalucía. Nos entrevistamos con dirigentes, incluso líderes históricos, de la UGT y de CCOO tanto en Madrid que en Barcelona, Bilbao y Sevilla. Mantuvimos también encuentros con representantes de USO, de ELA-STV y de la Intersindical Nacional de Trabajadores Gallegos (INTG).

Nos reunimos con el Presidente y los miembros del Tribunal Central de Trabajo. Celebramos también dos sesiones de trabajo con varios profesores universitarios, una en Madrid, la otra en Sevilla, presidida por Miguel Rodríguez Piñero. Visitamos diversas empresas, como RENFE, los Altos Hornos de Vizcaya, la fábrica de explosivos Rio Tinto, la SEAT y una explotación agrícola al norte de Sevilla.

\footnotetext{
${ }^{15}$ Sagardoy, Juan Antonio, León Blanco, David, El poder sindical en España, Madrid, Editorial Planeta, 1982

16 OIT, 1985, op.cit, págs. 24-30. En 1982, sobre las 262 empresas de más de 500 trabajadores (que empleaban un total entre 730000 y 740000 asalariados), alrededor de 70 por ciento eran miembros de la CEOE (Ministerio de Economía y Hacienda, Dirección general de la política económica, La negociación colectiva en 1982: principales características y tendencias, Madrid, Publicaciones de la Secretaria General Técnica, 1983, pág., 17).
} 
En todas las etapas de nuestro viaje fuimos recibidos con gran cordialidad, a pesar de las tensiones y de los problemas que se vivían el país en esta época. Por ello, el acceso a los edificios públicos y a muchas instituciones privadas exigía como requisito previo someterse a un registro corporal por miedo a los atentados. De hecho, durante nuestra visita en Bilbao, tuvo lugar un atentado contra una sede del BBVA. Además, durante nuestra estancia se produjeron dos accidentes aéreos en Barajas y un descarrilamiento en la línea ferroviaria entre Barcelona y Madrid, con gran preocupación para nuestras familias.

La misión confirmó la puesta en práctica de los cambios normativos descritos anteriormente e insistió sobre la necesidad de abordar algunas mejoras. No obstante, esta rápida transformación del sistema de relaciones laborales no podía hacerse sin algunos tanteos, sin fricciones y tampoco sin algunas deficiencias.

Los tanteos concernían por ejemplo a la definición de las funciones de los delegados sindicales y de las formas autónomas de representación de los trabajadores en la empresa, así como del papel del Estado, e incluso de las Comunidades Autónomas, en la negociación de acuerdos colectivos a un nivel más elevado ${ }^{17}$.

Las fricciones se relacionaban con las rivalidades, a veces muy enconadas, entre las diversas tendencias del movimiento sindical, siendo la devolución del patrimonio sindical de la antigua organización corporativa la principal causa de discordia. El sistema de relaciones profesionales presentaba aún lagunas claras, en primer lugar la ausencia de procedimientos eficaces para solucionar pacíficamente los conflictos colectivos de trabajo $^{18}$, incluso en la administración pública ${ }^{19}$. Todo ello lo analizaremos en el siguiente apartado.

\section{Puntos principales}

\subsection{La devolución del patrimonio de la antigua organización corporativa}

La devolución del patrimonio perteneciente a la antigua organización corporativa resultó uno de los temas espinosos a los que debía hacer frente el Gobierno democrático. Este patrimonio constaba de dos tipos de bienes: los que fueron incautados por el régimen franquista a las organizaciones de trabajadores y a ciertas asociaciones de empleadores, y luego transferidos al sindicato vertical al terminar la Guerra Civil (el patrimonio "histórico") y los ingresos de los que dicha organización dispuso ulteriormente, procedentes en particular de las cotizaciones obligatorias (el patrimonio "acumulado")

La cuestión fue sometida al CLS de la OIT que subrayó la importancia de recurrir a la consulta de las organizaciones representativas de empleadores y trabajadores para buscar

\footnotetext{
${ }^{17}$ Palomeque López, Manuel Carlos, "La negociación colectiva en España, 1978-1979. De la Constitución al Estatuto de los Trabajadores", Revista de política social, n 135, 1982, pág. 23; OIT, 1985, op. cit, pág. 129.

${ }^{18}$ Alonso Olea, Manuel, El Estatuto de los trabajadores. Texto y comentario breve, Madrid, Civitas, 1980 $\S 256$.

${ }^{19}$ Ojeda Avilés, Antonio, Derecho sindical, Madrid: Tecnos, 1980 págs. 387 y 412.
} 
una solución definitiva al problema de la afectación del patrimonio acumulado. La solución, añadió, debería inspirarse en el principio de la asignación de los bienes a la finalidad para la que estaban destinados, y no en el importe de las cuotas que pagaron unos y otros, respectivamente a la organización desaparecida. La devolución de los bienes confiscados debería ser objeto de negociaciones entre el Gobierno y los representantes de las organizaciones profesionales interesadas. Por decirlo en pocas palabras, el CLS no buscó definir a qué asociación deberían ir los bienes y en qué proporción, sino que únicamente indicó los criterios que permitirían dicho reparto entre las organizaciones profesionales existentes ${ }^{20}$.

La solución adoptada finalmente respetó estas recomendaciones, aunque su interpretación también generó alguna controversia. Algo que, sin duda, resultaba inevitable debido al considerable montante del capital que debía repartirse. El patrimonio inmobiliario acumulado fue cedido para su uso a las confederaciones sindicales en función de su representatividad. El Estado procedió a calcular el valor económico de los bienes incautados a los sindicatos históricos, con fuerte implantación antes de la Dictadura, en concreto de UGT y CNT, y les restituyó las cantidades correspondientes ${ }^{21}$

\subsection{Pactos sociales}

A fines de 1978 UGT y CCOO habían adquirido, sobre todo después de las elecciones sindicales, un peso considerable en la vida social del país. La elevada conflictividad de 1978 y la aún más importante del año siguiente mostraron el agotamiento de la forma autoritaria de encarar el proceso de elaboración de la política de rentas. Al mismo tiempo, la Comisión de Expertos para la Aplicación de los Convenios y Recomendaciones de la OIT (CEACR) había indicado que la adopción de medidas restrictivas violaba el derecho a negociar libremente sobre salarios y condiciones de trabajo (Conferencia internacional del trabajo, 1981:147). Ya al principio de los años 80, la gravedad del problema del desempleo impulsó a la CEOE, a la UGT y a $\mathrm{CCOO}^{22}$ a decidir una acción concertada contra el paro, que se plasmó en un Acuerdo nacional sobre el tema. Su consecuencia más inmediata fue el cambio de actitud del Gobierno que ya no impuso una pauta salarial, sino que la transformó en una mera "sugerencia" de respetar la inflación prevista para 1980, dejando la responsabilidad final en manos de los interlocutores sociales. El fruto fue el Acuerdo Marco Interconfederal (AMI) de enero de $1980^{23}$.

En los años siguientes, se repitió la misma política de diálogo social promovida por la OIT, especialmente de pactos sociales bi- o tripartitos de manera que constituyó un rasgo

\footnotetext{
${ }^{20}$ OIT, Boletín Oficial, Series B, No. 2, Informe 194 Comité de Libertad Sindical, caso No. 900 (España), Ginebra, OIT, 1979, §§238-262; OIT, Boletín Oficial, Series B, No. 2, Informe 202, Comité de Libertad Sindical, caso No. 900 (España), Ginebra, OIT, 1980, §§ 337-354.

${ }^{21}$ Cruz Villalón, Jesús, Compendio de derecho del trabajo, 10ª edición, Madrid, Editorial Tecnos, 2017, pág. 461; Sagardoy, Juan Antonio y León Blanco, David, El poder sindical en España, Madrid, Editorial Planeta, 1982, págs. 150-157.

${ }^{22}$ El País, 1981.

${ }^{23}$ Rodríguez Piñero, Miguel y González Ortega, Santiago, "Acuerdos interprofesionales, centralización de la negociación colectiva y Ley del Estatuto de los Trabajadores", Revista de política social, $\mathrm{n}^{\circ}$ 137, 1983, págs. 347-393; OIT, Situación sindical y relaciones laborales en España, Ginebra, OIT, 1985' págs. 83-84.
} 
característico de la escena laboral española, a pesar de algunos fracasos. La grave situación económica, unida a la amenaza constante de una crisis política que pudiera interrumpir el proceso democrático llevaron a los interlocutores sociales, y a sus propias bases de empresarios y trabajadores, a adoptar una actitud más conciliadora en sus relaciones laborales. Salvo algunas excepciones, parecían conscientes de la situación crítica que afectaba al país y se hallaban dispuestos a aunar esfuerzos en el empeño por superarla. De uno y otro lado, los dirigentes y la sociedad civil preferían la negociación a la confrontación ${ }^{24}$. Este diálogo social permitió combatir el paro con eficacia ${ }^{25}$ y generar un desarrollo económicamente impresionante.

\subsection{La ausencia de procedimientos eficaces de conciliación, mediación y arbitraje voluntario}

La misión de la OIT en 1983 señaló las lagunas del sistema de relaciones profesionales del país. Mencionó en primer lugar la ausencia de procedimientos eficaces de conciliación, mediación y arbitraje voluntario para tratar de encontrar una solución a los conflictos colectivos de trabajo. Añadió que la mejora de estos procedimientos no exigía forzosamente la adopción de una ley; también podía ser el fruto de un acuerdo concluido entre asociaciones empresariales y sindicatos.

De hecho, sabemos que enseguida se firmó un acuerdo en este sentido. La concertación social de la primera mitad de los años 80 había apuntado ya a la creación de procedimientos autónomos, extrajudiciales y extra administrativos, de solución pacifica de los conflictos. El AMI recogía un capítulo sobre la mediación, la conciliación y el arbitraje, y preveía un Comité paritario interconfederal. En algunos ámbitos autonómicos se habían desarrollado desde finales de los años 80 y la primera mitad de los 90, experiencias de sistemas de resolución autónoma de conflictos laborales sobre la base de acuerdos entre los interlocutores sociales de esos ámbitos, con participación directa de las organizaciones empresariales y sindicales en la gestión de los correspondientes órganos y procedimientos de mediación y arbitraje.

La implantación y desarrollo de un sistema de solución autónoma de los conflictos laborales recibió su principal y definitivo impulso con el primer acuerdo interprofesional de ámbito estatal sobre esta materia, el Acuerdo sobre Solución Extrajudicial de Conflictos Laborales (ASEC), firmado en enero de 1996 por las organizaciones sindicales y empresariales más representativas de ámbito estatal, CCOO, UGT, CEOE y CEPYME $^{26}$.

\footnotetext{
${ }^{24}$ OIT, op.cit, págs. 10-12.

${ }^{25}$ Reher, David-Sven, "Mercado de trabajo y empleo en España durante el siglo XX" en Pérez Fernández, José, Gascón Pedro, Sebastián, Carlos y Tedde de Lorca, Pedro (coord.): Estudios en homenaje a Luis Ángel Rojo Economía y cambio histórico, vol. II, Madrid: Editorial Complutense, 2009, págs.319-337; Toharia, Luis, "Activité, emploi et chômage en Espagne (1976-2007): une perspective évolutive et comparée", Travail et emploi, vol. 115, Julio-Septembre 2008, págs. 13-27.

${ }^{26}$ Consejo Económico y Social (5 de Junio de 2020): Dos décadas de solución autónoma de los conflictos laborales, http://www.ces.es/documents/10180/3828741/Cauces_31_pp29-39.pdf, págs. 31-32; Casas Baamonde, María Emilia, "La mediación laboral autónoma como alternativa al proceso" en García Murcia,
} 


\subsection{Las relaciones laborales en la Administración Pública}

Otro problema era la incertidumbre reinante acerca de las posibilidades de negociación colectiva o de participar de alguna otra manera en la determinación de las condiciones de trabajo, así como de efectuar una huelga en la Administración Pública ${ }^{27}$. La ratificación en 1984 del Convenio núm. 151 sobre las relaciones de trabajo en la administración pública (1978), contribuyó a acelerar la solución de estas dificultades.

\section{Años posteriores}

España es el país que ha ratificado el mayor número de convenios internacionales del trabajo: 133 y un protocolo (hasta el 25 de noviembre de 2021), de los cuales 87 están aún en vigor, 39 se han denunciado y dos instrumentos se han abrogado. Estos incluyen los Convenios considerados fundamentales por la OIT en su Declaración de 1998 relativa a los Principios y Derechos Fundamentales en el Trabajo y su Seguimiento ${ }^{28}$. También ha ratificado los 4 instrumentos llamados de gobernanza, considerados prioritarios por la Declaración de la OIT sobre Justicia Social para una Globalización Equitativa adoptada el 10 de junio de $2008^{29}$. Las últimas ratificaciones incluyen el Convenio sobre el trabajo marítimo, 2006 (MLC, núm. 186) y el Convenio sobre el marco promocional para la seguridad y salud en el trabajo, 2006 (núm. 187).

Además, también ha ratificado los Pactos de las Naciones Unidas sobre Derechos Civiles y Políticos y sobre Derechos Económicos, Sociales y Culturales, así como el Convenio Europeo para la Protección de los Derechos Humanos y de las Libertades Fundamentales y la Carta Social Europea. Está vinculada también por la Carta de los Derechos Fundamentales de la Unión Europea (UE).

Otro signo importante del reconocimiento internacional de la España democrática es que la OIT nombró en 1995 a Miguel Rodríguez Piñero y Bravo Ferrer miembro de su CEACR. Fue encargado del control de convenios fundamentales sobre libertad sindical y negociación colectiva. Quizás, no se conoce lo suficiente el papel que ha jugado en las relaciones entre la Organización internacional del Trabajo y España. No me refiero solamente a su participación clave en este Comité de expertos, sino al desarrollado durante la Dictadura. Sus anhelos en materia de derechos sociales permitieron a la OIT mantener su influencia en un país sin libertades, en particular sindicales. Su valentía en

Joaquín y Borrego Gutiérrez, Martín (coord.), I Congreso Universitario sobre Solución Autónoma de Conflictos Laborales, http://fsima.es/wp-content/uploads/Ponencia-I-Congreso-La-mediaci\%C3\%B3nlaboral-aut\%C3\%B3noma-M-Emilia-Casas.pdf,, 2015, págs.62-63

${ }_{27}$ Almansa Pastor José Manuel, "Los sujetos del derecho del trabajo y de la seguridad social. Revista de Trabajo", 1980, nºs 63 y 64, pág. 23.

${ }^{28}$ Los convenios sobre la libertad sindical y la protección del derecho de sindicación, 1948 (núm. 87), sobre el derecho de sindicación y de negociación colectiva, 1949 (núm. 98), sobre la abolición del trabajo forzoso, 1930 (núm. 29) y 1957 (núm. 105), sobre la edad mínima, 1973 (núm. 138) y sobre las peores formas de trabajo infantil, 1999 (núm. 182), sobre la discriminación (empleo y ocupación), 1958 (núm. 111) y sobre igualdad de remuneración, 1951 (núm. 100).

${ }^{29}$ El convenio sobre la inspección del trabajo, 1947 (núm.81), el convenio sobre política de empleo, 1964 (núm.122), el convenio sobre la inspección de trabajo (agricultura), 1969 (núm.129), el convenio sobre la consulta tripartita (normas internacionales del trabajo), 1976 (núm.144) 
esta época llena de peligros para quienes, como él, mantenían actitudes democráticas, permitió que la Organización mantuviese contactos en el país para salvar vidas y, poco a poco, para promover relaciones laborales más humanas. Hizo de intermediario en la llegada de la misión de la Organización en 1967 que impulsó los cambios descritos más arriba. Su sentido político, su capacidad de análisis y su compromiso democrático fueron esenciales para el éxito de una acción internacional.

Como para cada Estado miembro de la OIT, la CEACR formuló posteriormente ciertos comentarios relativos a la aplicación por parte de España de los convenios ratificados. El CLS ha recibido igualmente a lo largo del tiempo alegatos sobre problemas específicos en materia de relaciones laborales. Asociaciones profesionales presentaron también a la OIT reclamaciones basadas sobre el artículo 24 de su Constitución. Sin embargo, no creemos necesario analizar con mayor profundidad las observaciones y conclusiones de este periodo porque no presentaban una gravedad o una dimensión preocupante. Además, encontraron una solución aceptable para las partes interesadas.

La relación de España con la OIT y sus normas, después de la dictadura, fue una bella historia. No tengo mucho más que explicar. El país se integró sin mayor problema a la visión que los países de la Europa occidental tenían de la política social, incluso pudo considerarse un modelo al respecto. Ha aplicado con suma atención las normas de la OIT en materia de libertad sindical, de libre negociación colectiva y de igualdad de oportunidades y de trato. Repitámoslo: se dio preferencia a la concertación más que a la confrontación, lo que permitió eficazmente disminuir el desempleo y lograr un desarrollo económico considerable.

El Estado intentó aplicar el mismo método inspirado de la OIT para salir de la nueva crisis económica iniciada en 2008, pero con mucho menos éxito. En efecto, nuevamente tuvo que hacer frente a más desigualdades entre trabajadores estables y precarios, controversias sobre el ejercicio del derecho de huelga y un diálogo social bastante bloqueado. En estas circunstancias, se podía prever que crecerían el número de observaciones, de quejas y reclamaciones enviadas por las organizaciones profesionales, principalmente los sindicatos, y que aumentarían el número de casos y de comentarios de la $\mathrm{CEACR}^{30}$.

Las conclusiones adoptadas por los órganos de control han tratado sobre las medidas de flexibilización del mercado de trabajo, el paro y la precarización del empleo, los problemas propios a los migrantes y las restricciones alegadas de la libertad sindical y de la libre negociación colectiva. Problemas similares a los existentes en otros Estados que trataban de modernizar su economía, de adaptarse a los nuevos instrumentos de gestión de las empresas y a un mundo mucho más abierto. Sin embargo, en ninguno de estos

\footnotetext{
${ }^{30}$ Lozano Lares, Francisco, "La eficacia jurídica del concepto de trabajo decente", Revista internacional y comparada de relaciones laborales y derecho del empleo, vol.4 (4), 2016, págs.1- 36.; Malo, Miguel Ángel. "Collective bargaining reforms in Southern Europe during the crisis: impact in the light of international standards", en Pulignano, Valeria y Köhler, Holm-Detlev (coord.), Employment relations in an era of change, Bruselas, ETUI, 2016, págs.117-135.
} 
países, por ejemplo, en Grecia, la OIT logró aportar soluciones sociales plenamente satisfactorias.

Frente a estas cuestiones, he examinado en otra contribución ${ }^{31}$ las posibilidades de afinar estas propuestas o de perfeccionar las normas internacionales para tener más en cuenta las preocupaciones actuales de un mundo del trabajo muy diferente del que hemos conocido hasta hace pocos años. Las dificultades surgidas a partir de 2008 reflejan sobre todo la necesidad de los actores tradicionales de la escena social, incluso de la propia OIT, de ajustarse a un mundo de trabajo mucho más globalizado y digital. Nuestras sociedades sufren de la flexibilidad de las estructuras empresariales, lo que explica, en algunos casos, la inestabilidad del empleo que tanto les afecta ${ }^{32}$. Todavía no se ha reflexionado suficientemente sobre las limitaciones a la capacidad de los gobiernos de aplicar su propia política social en una era de globalización.

Dicho esto, no conviene mezclar el grano con la paja. El debate que se ha desarrollado sobre el futuro del trabajo y de la OIT con ocasión de su centenario no debe quedar en un diálogo de sordos entre quienes tienen una visión idealista o nostálgica de la acción de la Organización ${ }^{33}$, percepción que no corresponde a la realidad actual, y aquellos otros que profetizan su muerte si no cambia totalmente su estructura y sus medidas de acción ${ }^{34}$, carente de fundamento y realismo.

Tales afirmaciones pueden perjudicar la imagen de la institución y, por consiguiente, su capacidad de acción. Cualquier apreciación critica de las actividades actuales de la OIT, especialmente de su agenda del trabajo no debe ocultar lo esencial. Esta política prioritaria incluye programas importantes, dirigidos principalmente, pero no sólo, a los países en vía de desarrollo.

En particular, las normas internacionales de trabajo conservan una influencia significativa en las discusiones académicas, en la elaboración de las políticas y en la revisión de los derechos nacionales. Además de los procedimientos de control que generan un impacto importante, la Organización puede utilizar algunas medidas para la implementación de sus normas como son la cooperación técnica, los diferentes tipos de mediaciones y el soft law. Asimismo, sus normas siguen constituyendo un referente en los sistemas generalizados de preferencias de los EEUU, de la UE y de varios países, en los tratados bi- o multilaterales de comercio y en los códigos de conducta de grandes empresas o en otras iniciativas privadas. Subrayarlo no significa negar las dificultades y la necesidad de sugerir otras opciones para disminuirlas.

\footnotetext{
31 Servais, Jean-Michel, "España y las normas de la OIT o cómo renovar una bella historia" en Gil y Gil, Jose Luis (coord.), España y la OIT. 100 años de diálogo en un mundo cambiante, Madrid, Ediciones Cinca, 2018, págs. $27-57$

${ }^{32}$ Didry, Claude, L'institution du travail. Droit et salariat dans l'histoire, Paris, La Dispute, 2016.

${ }^{33}$ Véase por ejemplo J.L Gil y Gil, "La declaración del centenario de la OIT para el futuro del trabajo", Revista General de Derecho del Trabajo y de la Seguridad Social núm. 57, noviembre de 2020.

${ }^{34}$ Véase por ejemplo A. Ojeda Avilés en su conferencia "Solución de conflictos por la OIT: ¿una limitación congénita?" organizada por la Asociación Argentina de Derecho del Trabajo y de la Seguridad Social, el 10 de marzo de 2021.
} 
La OIT desempeñó y desempeña actualmente un papel significativo en la defensa de los derechos fundamentales en el ámbito laboral, incluso en la transición de Estados totalitarios a regímenes liberales. Su Declaración relativa a los Principios y Derechos Fundamentales en el Trabajo de 1998 sigue siendo la columna vertebral de su acción. Su experiencia y sus normas acompañan a gobiernos e interlocutores sociales en la defensa y la ilustración de sus valores.

Apenas 15 años después del cambio de régimen en España, Europa conoció otra transición de un sistema de partido único a la democracia. La experiencia de su país, más que otras revoluciones de este tipo, ayudó a la Organización internacional del Trabajo a acompañar los verdaderos trastornos acaecidos en la Europa oriental. Lo cual se debe al carácter modélico de la transición democrática en España, a la profunda cooperación de la OIT con la joven democracia y a iniciativas españolas para apoyar a partir de 1989 a los antiguos países comunistas y facilitar su propia transición.

Me refiero, por ejemplo, a una reunión organizada por Juan Antonio Sagardoy en 1990 que agrupó a juristas de estos países con colegas españoles, franceses y belgas para intercambiar experiencias en materia de relaciones laborales o a la cooperación entre la Universidad de Lódz en Polonia y la Escuela Superior de Administración y Dirección de Empresas de Barcelona que permitió un intercambio de profesores, pasantías de estudiantes y una conferencia sobre el Derecho del trabajo ${ }^{35}$, así como la importancia de los sindicatos en la democratización de los dos países que mencioné anteriormente.

Finalmente, a partir de ahora trataré de extraer, a modo de conclusión, algunas lecciones y reflexiones de estas experiencias. Así, me ocuparé sucesivamente de los métodos de interpretación y de aplicación de los textos jurídicos sobre las libertades civiles y sociales y del papel de las instituciones nacionales en la transición de un sistema dictatorial a uno democrático.

\section{Algunas reflexiones finales sobre una transición particularmente corta y exitosa}

\section{Los métodos de interpretación y de aplicación de los instrumentos jurídicos sobre las libertades civiles y sociales}

Un buen análisis comparativo de las normas internacionales y de la legislación nacional no puede considerar los textos por sí solos. Debe tener en cuenta la forma en que se ponen en práctica. Premisa elemental, sin duda, pero de ejercicio peligroso. No obstante, debe efectuarse una distinción clara entre los argumentos jurídicos y los puramente socioeconómicos. Estos últimos no deben servir de pretexto para defender lo indefendible y afirmar que dos disposiciones ofrecen las mismas soluciones cuando las diferencias son jurídicamente evidentes.

\footnotetext{
${ }^{35}$ Seweryński, Michal y Marzal, Antonio (coord.): Changements politiques et droit du travail. Perspective polono-espagnole, Lódz, Wydawniçtwo Univewersytetu Lódzkiego, 1992.
} 
El ejemplo siguiente ilustra lo que intento demostrar. Parte de la aplicación de los derechos fundamentales del trabajo en los antiguos regímenes socialistas con economías planificadas en Europa central y oriental que habían ratificado los convenios sobre la igualdad de tratamiento y oportunidades y otros instrumentos fundamentales de la OIT. Como regla general, sus Constituciones reconocieron un buen número de libertades civiles y su legislación preveía su protección integral en textos específicos como el Código Civil o Penal. Sin embargo, esas mismas disposiciones establecían condiciones para el ejercicio de esas libertades, por temor a que se utilizaran para perjudicar al sistema político, económico y social establecido. Esas restricciones permitieron a las autoridades rechazar, por ejemplo, la creación de organizaciones cuyo propósito no correspondía a los objetivos de construir una sociedad socialista. De una manera u otra, el ejercicio de las libertades individuales dependía, en España, de condiciones similares.

Pero, ¿quién podía decidir si una actividad estaba o no en sintonía con los intereses y la promoción del sistema establecido? La respuesta a esa pregunta generó otras sobre la extensión de los poderes del Ministerio del Interior en ausencia de jurisdicciones independientes encargadas de verificar la legalidad y las operaciones de las administraciones. También planteó interrogantes sobre la independencia del poder judicial especialmente, dado que las fórmulas legales establecidas, por ejemplo, en el Código Penal, tenían un alcance genérico y, por lo tanto, eran susceptibles de interpretaciones diferentes. En resumen, ¿dónde se encontraban los límites, si los había, al poder discrecional de la Administración? Ese poder se ejercería de manera particularmente discrecional cuando la Administración tuviese miedo de que el orden social existente pudiera verse afectado. Las autoridades públicas de estos países desempeñaron un papel esencial en la interpretación y aplicación de los textos legales sobre estas libertades básicas, y esto condujo inevitablemente a su parálisis y al abuso frecuente de la autoridad.

En última instancia, la ley se consideraba un medio para la consolidación y el desarrollo de una sociedad socialista. Los textos jurídicos se interpretaron utilizando un método teleológico. De hecho, innumerables juristas de los países comunistas subrayaron que los derechos reconocidos no tenían un contenido abstracto y que debían cumplirse en una sociedad real, que dependía del sistema económico y social ${ }^{36}$. Esto obviamente no protegió al intérprete del subjetivismo.

La cuestión dio lugar a una larga controversia respecto a la observancia por la URSS y otros países comunistas de los convenios de la OIT en materia de derechos fundamentales de los trabajadores (libertad para formar asociaciones de empleadores y trabajadores, ausencia de trabajo forzoso, igualdad de oportunidades y trato en el empleo).

Los gobiernos de esos países sostuvieron durante largo tiempo que las condiciones económicas y sociales existentes constituían un factor que debía tenerse en cuenta en la

\footnotetext{
${ }^{36}$ También Ivanov, Semion, "Sur les études comparatives en droit du travail". Revue internationale de droit comparé, vol.37 (2), 1985, págs.379-389.
} 
evaluación de los Convenios sobre esos derechos. Expresaron reservas con respecto a las opiniones de la CEACR relativas a la aplicación en sus países de los convenios correspondientes y reiteraron que, cuando se analizaba su cumplimiento, debían tomarse en consideración las condiciones prácticas. Afirmaban que era imposible obtener un cuadro claro de la organización, funciones y derechos de los sindicatos sin considerar la estructura económica, política y legal del Estado socialista.

En suma, los países de signo comunista creyeron que los convenios internacionales de trabajo, considerados universales por naturaleza, podían diversificarse teniendo en cuenta las distintas realidades sociales, siendo todas ellas conformes con las normas de la OIT. Consideraban así que los métodos por los cuales esos instrumentos se tornaban efectivos en los países capitalistas, y el resultado de su implementación, no eran los únicos que respetaban los Convenios. Afirmar el contrario era en sus juicios incompatibles con los principios fundamentales del Derecho Internacional, basados en la pacífica coexistencia.

La mayoría de los miembros de los órganos del control de la OIT rechazaron esos argumentos. La CEACR admitió que las diferentes realidades sociales que prevalecían en los diferentes sistemas políticos y sociales podían estar en armonía con un convenio dado de la OIT y, a la inversa, que las discrepancias entre el derecho o la práctica nacional y un instrumento ratificado claramente podía surgir en países pertenecientes a uno u otro sistema. Sin embargo, subrayó el siguiente punto: al evaluar la legislación y práctica nacionales con respecto a los convenios de la OIT, su rol es el de definir si las disposiciones de un determinado convenio están siendo aplicadas, sin importar cuáles son las condiciones económicas y sociales dominantes en el país analizado. Las obligaciones dimanantes de ese convenio son constantes y uniformes para todos los Estados, sujetos solamente a las excepciones que el propio convenio autoriza. Al llevar a cabo su tarea, la CEACR se guía únicamente por las normas contenidas en los Convenios, aunque nunca pierde de vista el hecho de que las medidas para su implementación pueden diferir de un Estado a otro. Se trata de normas internacionales, y la manera en que se examina su cumplimiento debe ser uniforme y no verse afectada por conceptos derivados de un sistema social y económico específico ${ }^{37}$

En resumidas cuentas, se trata de una cuestión de interpretación que se plantea tanto en la legislación nacional, como en el Derecho Comparado y en el Derecho Internacional: nada permite hacer una distinción si la norma aplicable no la hace. Por supuesto, el juez en un caso criminal, por ejemplo, considera circunstancias atenuantes; lo hace, sin embargo, sobre la base del texto legal que le autoriza a hacerlo. Lo mismo sucede con todas las ramas del Derecho. En este caso, esta opinión ha recibido el apoyo de la mayoría de los expertos y de los delegados de la OIT.

No obstante, las observaciones que he realizado más arriba requieren algunas precisiones suplementarias. Una disposición legislativa nacional o internacional puede

\footnotetext{
${ }^{37}$ En particular Conferencia internacional del trabajo, (1987), Informe III (Parte 4A) $73^{\circ}$ sesión, Ginebra, OIT $\S 20$.
} 
autorizar expresa o indirectamente excepciones a la regla común en atención a las condiciones económicas y sociales. Esto sería posible porque derivaría de las cláusulas y dispositivos de flexibilidad que se incorporan en los instrumentos. La consideración de esos factores depende en esas hipótesis de la formulación de los textos analizados. Para facilitar su ejecución, deben estipular claramente quién valora esas circunstancias, en qué medida y con qué consecuencias. Generalmente, tanto los Convenios Internacionales como las legislaciones nacionales tienen expresamente en cuenta esas condiciones en la elección de los medios de aplicación. En todo caso, el control de su conformidad abarca no sólo la letra de los textos sino también la manera en que se ejecutan. Este ejercicio no es nada fácil y puede resultar arriesgado en la práctica.

Más aún, los factores económicos y sociales son una parte necesaria de la estrategia ideada después para superar las dificultades identificadas en la aplicación de los convenios ratificados. Que esos instrumentos tengan o no verdadero impacto depende en gran medida de que formen o no parte de una política social genuina.

Varios países en desarrollo, particularmente en Asia, han intentado más recientemente que la implementación de los convenios se evalúe de manera flexible y teniendo en cuenta el contexto socioeconómico. Los órganos de control de la OIT y una mayoría de los gobiernos de su Consejo de Administración se han resistido a aceptar este argumento y, aunque admiten los dictados del progreso económico y la lucha por eliminar la pobreza, también mantienen que las políticas de austeridad, que han tenido que adoptarse inevitablemente, tendrían que respetar los principios de equidad y no obligar a los más desposeídos a soportar la carga del desarrollo.

Consideran que las disposiciones internacionales del trabajo no son simplemente preocupaciones morales loables o irrealistas, especialmente en periodos de crisis. Las normas de la OIT tienen un significado, tienen un peso importante en la promoción de un crecimiento socio-económico equilibrado. Son también normas precisas que los Estados están obligados a respetar cuando han asumido el compromiso de hacerlo. Los tiempos difíciles no constituyen, en consecuencia, un argumento para relajar su aplicación. Si estas normas están escritas en términos flexibles y pueden adaptarse a diferentes niveles de desarrollo y diferentes sistemas legales, económicos o sociales, no puede emplearse la misma flexibilidad cuando se trata de evaluar el grado en que se aplica en un país determinado un Convenio en los términos en que se encuentra redactado.

La Conferencia no ha sido indiferente sin embargo a los numerosos obstáculos afrontados por los países en vías de desarrollo que se esfuerzan por alcanzar el nivel fijado por las normas de la OIT, obstáculos que surgen de la situación económica, de los modestos recursos, a veces también de la insuficiencia de sus estructuras, técnicas y administradores. Una abrumadora mayoría de Estados considera que debe efectuarse un esfuerzo mucho mayor en favor de esos países, en particular a través de los programas de cooperación técnica. 


\section{El papel de las instituciones nacionales}

Antes del cambio de régimen en España y de la apertura del Muro de Berlín, ya se implementó una política laboral y social en los sistemas ultra centralizados de Europa Central y Oriental por medio de una proliferación de regulaciones, estatutos, decretos, instrucciones administrativas de obligado cumplimiento. El mismo problema existe hoy en otros Estados totalitarios.

Es cierto que esta abundancia de prescripciones legales ha provocado que su supervisión sistemática sea más bien aleatoria. Además, el enfoque creciente en la productividad, debido a la competencia con las economías liberales, ha conducido en la práctica a una menor atención a la aplicación de las normas protectoras y a una relajación de los controles. Esta acumulación de normas, dentro de un sistema político centralizado y autoritario, ha favorecido, ya lo mencioné, el poder de la administración en la distribución de las funciones del Estado, tanto más considerables que los recursos judiciales contra sus decisiones fueron limitados y que no hubo una negociación colectiva real, con significado tradicional de estas palabras, entre empresarios y sindicatos.

La limitación de los poderes del gobierno, la verdadera independencia de los tribunales y de los actores sociales modifican este esquema en profundidad. Menos poder estatal también significa menos reglas estatales $\mathrm{y}$, cuando corresponda, el desarrollo de convenios colectivos libremente negociados. En Europa continental, los empresarios y los sindicatos también participan con frecuencia en la elaboración de normas laborales, legislativas y gubernamentales.

Sólo se asiste a un cambio de competencias del funcionario hacia el juez de dos maneras. En primer lugar, dado que las leyes no regulan todas las circunstancias, se confiere al juez una mayor facultad de apreciación y de decisión. Además, los sistemas democráticos otorgan normalmente a los tribunales competencia para controlar los actos de la administración. Esto constituye incluso una de sus características esenciales. Al mismo tiempo, desaparece la interpretación discrecional del funcionario supervisor. Las administraciones de trabajo mantienen la tarea de inspección siempre que resulta necesario, pero afirman cada vez con mayor frecuencia su papel de difusión de la información y de inspiración de políticas donde lo social no se sacrifique a la economía.

\section{Bibliografía}

Alonso Olea, Manuel, El Estatuto de los trabajadores. Texto y comentario breve, Madrid, Civitas, 1980.

Almansa Pastor José Manuel, "Los sujetos del derecho del trabajo y de la seguridad social. Revista de Trabajo", 1980, nos 63 y 64, págs. 13-26.

Casas Baamonde, María Emilia, "La mediación laboral autónoma como alternativa al proceso" en García Murcia, Joaquín y Borrego Gutiérrez, Martín (coord.), I Congreso Universitario sobre Solución Autónoma de Conflictos Laborales, http://fsima.es/wp- 
content/uploads/Ponencia-I-Congreso-La-mediaci\%C3\%B3n-laboralaut\%C3\%B3noma-M-Emilia-Casas.pdf,, (2015), págs. 59-95.

Cruz Villalón, Jesús, Compendio de derecho del trabajo, 10ª edición, Madrid, Editorial Tecnos, 2017.

De la Villa Gil, Luis Enrique, Panorama de las relaciones laborales en España, Madrid, Editorial Tecnos, 1983.

Didry, Claude, L'institution du travail. Droit et salariat dans l'histoire, Paris, La Dispute, 2016.

Gil y Gil, Jose Luis (coord.), España y la OIT. 100 años de diálogo en un mundo cambiante, Madrid, Ediciones Cinca, 2018,.

Gil y Gil, Jose Luis, "La declaración del centenario de la OIT para el futuro del trabajo", Revista General de Derecho del Trabajo y de la Seguridad Social núm. 57, noviembre de 2020.

Ivanov, Semion, "Sur les études comparatives en droit du travail". Revue internationale de droit comparé, vol.37 (2), 1985, págs.379-389.

Lozano Lares, Francisco, "La eficacia jurídica del concepto de trabajo decente", Revista internacional y comparada de relaciones laborales y derecho del empleo, vol.4 (4), 2016, págs.1- 36.

Malo, Miguel Ángel. "Collective bargaining reforms in Southern Europe during the crisis: impact in the light of international standards", en Pulignano, Valeria y Köhler, HolmDetlev (coord.), Employment relations in an era of change, Bruselas, ETUI, 2016, págs.117-135.

Ojeda Avilés, Antonio, Derecho sindical, Madrid: Tecnos, 1980.

Palomeque López, Manuel Carlos, "La negociación colectiva en España, 1978-1979. De la Constitución al Estatuto de los Trabajadores", Revista de política social, n 135,1982 , págs. 7-43.

Reher, David-Sven,"Mercado de trabajo y empleo en España durante el siglo XX" en Pérez Fernández, José, Gascón Pedro, Sebastián, Carlos y Tedde de Lorca, Pedro (coord.): Estudios en homenaje a Luis Ángel Rojo Economía y cambio histórico, vol. II, Madrid: Editorial Complutense, 2009, págs.319-337.

Rodríguez Piñero, Miguel y González Ortega, Santiago, "Acuerdos interprofesionales, centralización de la negociación colectiva y Ley del Estatuto de los Trabajadores", Revista de política social, $\mathrm{n}^{\circ} 137,1983$, págs. 347-393.

Sagardoy, Juan Antonio, León Blanco, David, El poder sindical en España, Madrid, Editorial Planeta, 1982. 
Servais, Jean-Michel, "España y las normas de la OIT o cómo renovar una bella historia" en Gil y Gil, Jose Luis (coord.), España y la OIT. 100 años de diálogo en un mundo cambiante, Madrid, Ediciones Cinca, 2018, págs. 27-57.

Seweryński, Michal y Marzal, Antonio (coord.): Changements politiques et droit du travail. Perspective polono-espagnole, Lódz, Wydawniçtwo Univewersytetu Lódzkiego, 1992.

Toharia, Luis, "Activité, emploi et chômage en Espagne (1976-2007): une perspective évolutive et comparée", Travail et emploi, vol. 115, Julio-Septembre 2008, págs. 13-27.

\section{Anexo}

Conferencia internacional del trabajo (1981), Informe III (parte 4A), 67 reunión, Ginebra, OIT.

Conferencia internacional del trabajo (1987), Informe III (Parte 4A) $73^{\circ}$ sesión, Ginebra, OIT.

Consejo Económico y Social (5 de Junio de 2020): Dos décadas de solución autónoma de los conflictos laborales, http://www.ces.es/documents/10180/3828741/Cauces_31_pp29-39.pdf

Ministerio de Economía y Hacienda, Dirección general de la política económica, La negociación colectiva en 1982: principales características y tendencias, Madrid, Publicaciones de la Secretaria General Técnica, 1983.

OECD (4 de junio de 2020), Trade Union - OECD Statistics stats.oecd.org > Index > DataSetCode $=$ TUD

OIT, La situación laboral y sindical en España, Ginebra, OIT, 1969.

OIT, Boletín Oficial, Series B, No. 2, Informe 194 Comité de Libertad Sindical, caso No. 900 (España), Ginebra, OIT, 1979.

OIT, Boletín Oficial, Series B, No. 2, Informe 202, Comité de Libertad Sindical, caso No. 900 (España), Ginebra, OIT 1980.

OIT, Situación sindical y relaciones laborales en España, Ginebra, OIT, 1985. 